\title{
Textile fibers resistant to biodestruction is a way to improve indoor ecological conditions
}

\author{
Ksenia Illarionova $^{1^{*}}$, Irina Asfondiarova ${ }^{1}$, and Sergei Grigorev ${ }^{2}$ \\ ${ }^{1}$ Institute of Industrial Management, Economics and Trade, Peter the Great St. Petersburg Polytechnic \\ University, Saint-Petersburg, Russia \\ ${ }^{2}$ N. I. Vavilov All-Russian Institute of Plant Genetic Resources, Saint-Petersburg, Russia
}

\begin{abstract}
The aim of research was to observe and to describe biodestructions of fabrics that usually used inside a home, to estimate the destruction (total number of destruction " $\mathrm{N}$ " and destruction index " $\mathrm{K}$ "). The samples of fabrics were placed into a thermostat in sterile Petri dishes on moistened sterile filter paper in order to stimulate the microflora occurred on fibers. Incubation carried out in a thermostat at a $+24-28{ }^{\circ} \mathrm{C}$, humidity of $90-100 \%$ and exposed for 8 month. The samples examined with a microscope. As a result of the study of fiber's damage, the types of damage were identified as follow: layering, fretting, mottling, fouling, spotting, swelling, granular disintegration, delamination, thinning, and damage of the fiber wall. Initially the most destructed was detected sample of natural silk and hemp according to the highest value of destruction index $\mathrm{K}$. However, after 8 months of exposure, this sample turned out to be the most resistant to biodegradation. The data obtained based on the evaluation of the biostability of fabrics made from various textile fibers showed that the usage of natural silk, hemp and polyester able to supply textile with resistance to biodegradation by spontaneous microflora.
\end{abstract}

\section{Introduction}

Textile goods themselves are to various degrees subject to biodestruction, resulting from the activity of microbiota [1]. Textiles of diverse composition for different uses may serve as the media conducive to the development of various microorganisms that produce mycotoxins which hit the airways [2]. Inhaling such products of microbiota in apartments, office facilities (curtains, wallpapers) or workplaces carries the risk of serious complications in the lungs. A possible occupational risk of toxins exposure has been revealed $[3,4]$. Bast textile fibers processing and spinning technologies promote microbiological pollution [5,6]. Elementalized hemp is suitable for use in textiles for various purposes [7] The works of a number of authors were aimed at finding solutions for the resistance of textiles to biological degradability during exploitation [8-10].

\section{Purpose of investigations}

The aim of research was to observe and to describe biodestructions of fabrics that usually used for indoor home, to estimate the destruction (total number of destruction 
"N" and destruction index "K" of fibers and select samples which are the most resistant to damage by spontaneous home microflora.

\section{Material and methods}

Samples of blended fabrics made of cotton, hemp, natural silk, viscose and polyester have been used in the study of natural biodegradation of textile fibers, Table 1.

Table 1. Material for the research. Structural characteristics of evaluated blended fabric samples.

\begin{tabular}{|c|c|c|c|}
\hline Sample & $\begin{array}{c}\text { Surface density } \\
\text { of fabric, } \mathbf{g} / \mathbf{m}^{\mathbf{2}}\end{array}$ & $\begin{array}{c}\text { Weaving type and } \\
\text { finishing }\end{array}$ & Fibrous composition (\%) \\
\hline 1 & 390 & Twill, melange & $\begin{array}{c}\text { Wool (40), polyester (30), hemp } \\
\text { (30) }\end{array}$ \\
\hline 2 & 213 & $\begin{array}{c}\text { Hopsack, unbleached } \\
\text { brown }\end{array}$ & $\begin{array}{c}\text { Wool (40), polyester (30), hemp } \\
(30)\end{array}$ \\
\hline 3 & 205 & Hopsack, melange & Wool (40), polyester (30), hemp \\
$(30)$
\end{tabular}

Fabric samples were kept in humidity and temperature lab conditions favorable for the development of spontaneous microflora of fibers that caused destruction. To stimulate the development of spontaneous microflora of textile fibers, the studied fiber samples were placed in sterile Petri dishes on sterile filter paper and kept in a thermostat at a temperature of $28 \pm 2{ }^{\circ} \mathrm{C}$ and a relative air humidity of $90-100 \%$ for 8 months. After a required time, the fiber samples were washed out in sterile water, then dried in air until the required humidity. Fibrous structure was examined under a microscope (Table 2).

The assessment of the degree of fiber damage was carried out using a microscope, revealing all types of morphological changes in the fibers with the subsequent calculation of the destruction index " $\mathrm{K}$ ". Depending on the index of biodegradation "K", the fiber is referred to the corresponding degree of destruction. The change in the biodegradation index " $\mathrm{K}$ " of the fiber in the range $0<\mathrm{K}(\mathrm{x} 1, \mathrm{x} 2, \mathrm{x} 3)<0.3$ corresponds to the initial changes in the fiber surface that do not affect its internal structure; in the range $0.3<\mathrm{K}(\mathrm{x} 1, \mathrm{x} 2, \mathrm{x} 3)<3.55-$ means the destruction of the surface and internal sections of the fiber, accompanied by initial changes in its structure, and in the " $\mathrm{K}$ " range between $3.55<\mathrm{K}(\mathrm{x} 1, \mathrm{x} 2, \mathrm{x} 3)<42.25$ means deep biological destruction of the fiber structure at all levels. All fiber samples were studied in two factors design. First fiber group have been stored in a thermostat in order to observe the fiber's destruction after keeping in favorable for fungus development conditions. This group of samples named in the research as "exposed samples". The alternative second design was as follow accessions of cotton did not exposed in thermostat. These samples mentioned in the research as "source samples". The results of the analysis were processed using the ANOVA analysis of the Statistica 10.0 (StatSoft Inc., USA). 
Table 2. Results of microscopy of source textile fibers, magnification $x 40$.

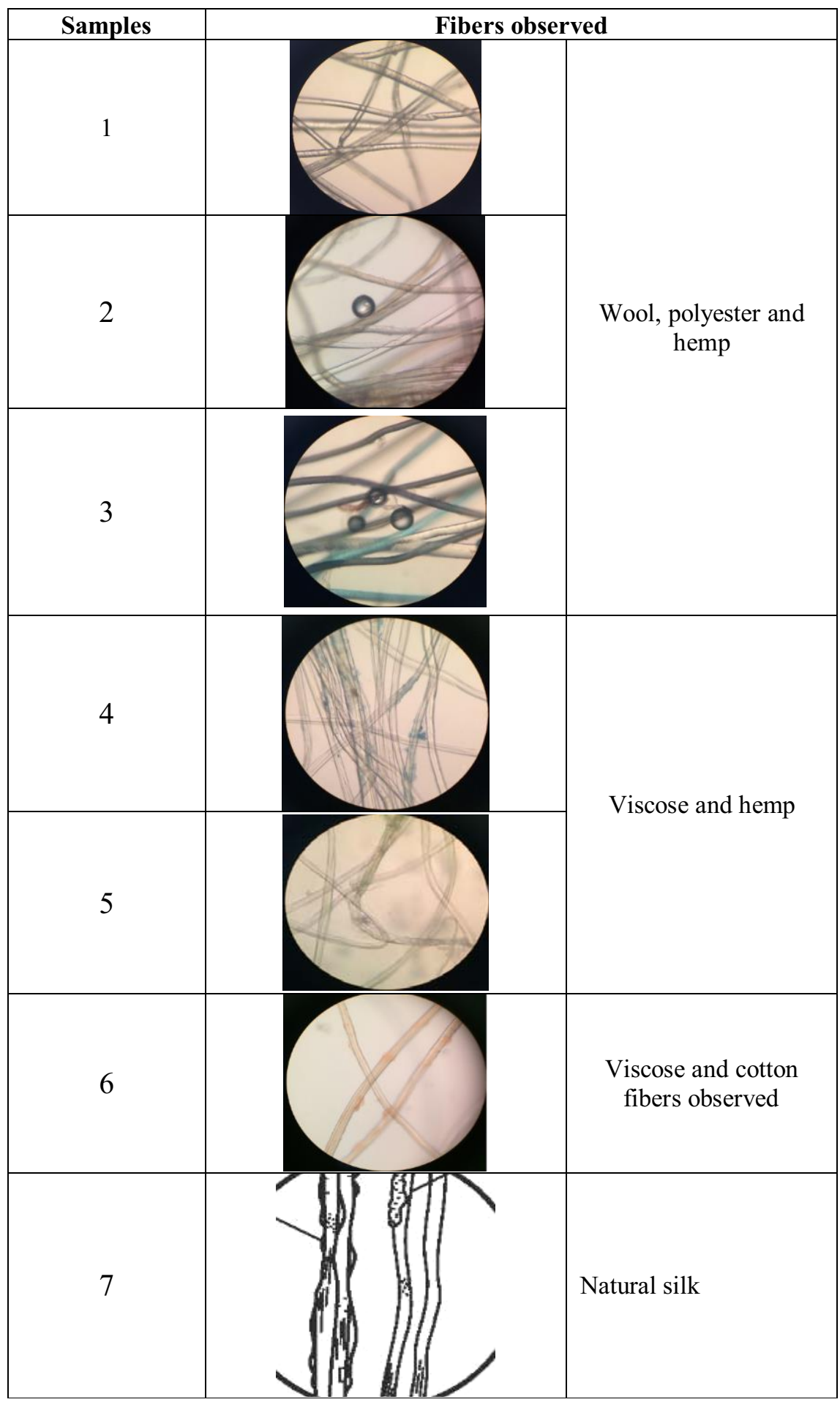




\section{Results and discussion}

As a result of the study of fibers damage, the following types of damage were identified as follow: layering, fretting, mottling, fouling, spotting, swelling, granular disintegration, delamination, thinning, and damage of the fiber wall.

Fouling and spotting of the fiber were manifested in the formation of microflora cells and products of its vital activity on fiber's surface, which were well stained with a water-alcohol solution of erythrosine. This kind of association of microorganisms in certain areas of the fiber caused a change of fiber's surface.

Fretting appeared in the form of microcracks up to 1 micron in size during the growth of microflora on the surface and inside the fiber. The process of bacterial growth was accompanied by an increasing biomass of destructured fibers and biochemical decomposition reactions. The total number, length and depth of microcracks increased. The predominance of longitudinal cracks occurred, which led to the destruction of the fiber.

Wall damage - the fiber surface is slightly or deeply damaged. Sometimes this kind of damage was clearly visible with marked edges. The fiber surface was significantly loosened and amorphous. Different sections were separated from the fiber.

The bulges were formed as result of the intensive microflora's growth in separated fiber sections. Sometimes microflora penetrated into the inner sections of the fiber causing the formation of spherical swellings with gap of a section of the fiber or the entire fiber. This damage occurs mainly in fibers which had pores and voids.

Thinning - damage was found in fibers with a high density, which made it difficult for the diffusion of enzymes into the fiber. Destruction started from the surface. Fiber destruction in layers. When the fiber core is broken, the fiber is "bleached". The outer shell is preserved. This damage occurred during destruction inside the fiber. The fiber core becomes available to the degrading enzymes rather than the sheath.

Layering is a deep and strong destruction of the fiber, which was accompanied by a disruption of the bonds between the fibril complexes and within individual fibrils.

Granular disintegration is the most obvious destruction as a result of disorientation of macromolecules. Disruption of intermolecular and intramolecular bonds was found. The fiber looked like an accumulation of granular conglomerates with products of microflora metabolism.

The revealed types of destruction had a different effect on the degree of fiber destructions. A quantitative assessment of the degree of fibers damage by microorganisms was carried out taking into account the characteristics of the type of fiber and types of damages. After studying the fiber's defects, damages were classified and conditionally divided into 3 classes: A, B and C.

Class A was characterized by a number of initial changes on the fiber's surface. Insignificant growth by microorganisms and the presence of products of their metabolism, weak spotting and freakiness.

Class B combined stronger manifestations of destruction: deep freakiness, mottling, swelling, thinning, damage the fiber's wall.

Class C was characterized by significant damage - deep freakiness, deep damage of the fiber wall (sheath and core), and fiber disintegration to separated conglomerates.

Damage of synthetic and artificial fibers was detected on the fiber's surface. Prevailed defects were observed as a dents, cracks and chips.

From Table 1 it follows that the highest surface density among the studied hempwool fabrics was observed in sample 1 (390), and among hemp-viscose fabrics sample 5 (240), which indicated their high strength and probable resistance to biodegradation due to low aeration. An increase in density is associated with an 
increase in surface density and rigidity. The low density correlated with the high porosity of the fabric and, as a result, the increased air permeability and moisture absorption capacity. Analysis of biodegradation of blended fabrics presented in Table 2 .

Samples 1, 3 and 5 had significant amount of fibers with mottling and wall damage. In sample 2, after 8 months, the amounts of fouling and swollen fibers increased, in samples 4 and 6 the amounts of fouling, granular disintegration and swollen fibers significantly increased (class B).

Analysis of the biostability of fabric samples showed that among the studied hempwoolen fabrics sample $3(0.88)$ had the highest destruction index, and among hemp-viscose fabrics sample 5 (0.90), which indicated their low biostability (Table 3 ).

Samples 1 and 4 were characterized by the highest degree of biostability, since they had the lowest values of the destruction index K, equal to 0.73 and 0.85 , respectively (Table 3 ).

Table 3. Biodestruction of source and exposed blended fabric samples, means.

\begin{tabular}{|c|c|c|c|c|}
\hline \multirow{2}{*}{ Samples } & \multicolumn{2}{|c|}{ Source samples } & \multicolumn{2}{c|}{ Exposed samples } \\
\cline { 2 - 5 } & $\begin{array}{c}\text { Total number } \\
\text { of destructions }\end{array}$ & $\begin{array}{c}\text { Destruction } \\
\text { index "K" }\end{array}$ & $\begin{array}{c}\text { Total number } \\
\text { of destructions }\end{array}$ & $\begin{array}{c}\text { Destruction } \\
\text { index "K" }\end{array}$ \\
\hline 1 & 12 & 0,14 & 67 & 0,73 \\
\hline 2 & 12 & 0,17 & 75 & 0,82 \\
\hline 3 & 13 & 0,16 & 81 & 0,88 \\
\hline 4 & 15 & 0,15 & 81 & 0,85 \\
\hline 5 & 16 & 0,12 & 83 & 0,90 \\
\hline 6 & 15 & 0,11 & 80 & 0,87 \\
\hline 7 & 8 & 0,39 & 80 & 0,65 \\
\hline 8 & 13 & 0,12 & 85 & 0,76 \\
\hline 9 & 13 & 0,13 & 89 & 0,87 \\
\hline
\end{tabular}

Among the samples numbered 4, 5 and 6 (hemp-viscose), a large amount of microflora overgrowth and speckles was found. Samples 1 and 2 (hemp-polyester) had an increase in granular decay and swollen fibers. In sample 2, the amount of microflora overgrowth, speckling, and granular decay increased significantly.

The results of analysis of variance for the mean (ANOVA) indices of the total number of damages $\mathrm{N}$ (Figure 1) revealed that the fabric containing natural silk and hemp (sample 7) and fabrics of samples 1 and 2 containing equal parts of wool, polyester and hemp were significantly low damaged.

However, after 8 months of being in a humid and warm environment, which were favorable for the development of pectolotic microflora, the greatest amounts of total damage of all classes was found in the fabrics containing cotton and hemp (sample 9), and significantly low in damage - sample 1 containing equal parts of polyester, wool and hemp (Figure 2).

It is noteworthy that initially the most destructed was sample of fabric 7 with natural silk and hemp according to the highest value of destruction index K (Figure 3). However, after 8 months of exposure, this sample turned out to be the most resistant to biodegradation according to the $\mathrm{K}$ index (Figure 4), and the most destroyed by microflora was sample 5, containing viscose and hemp. 


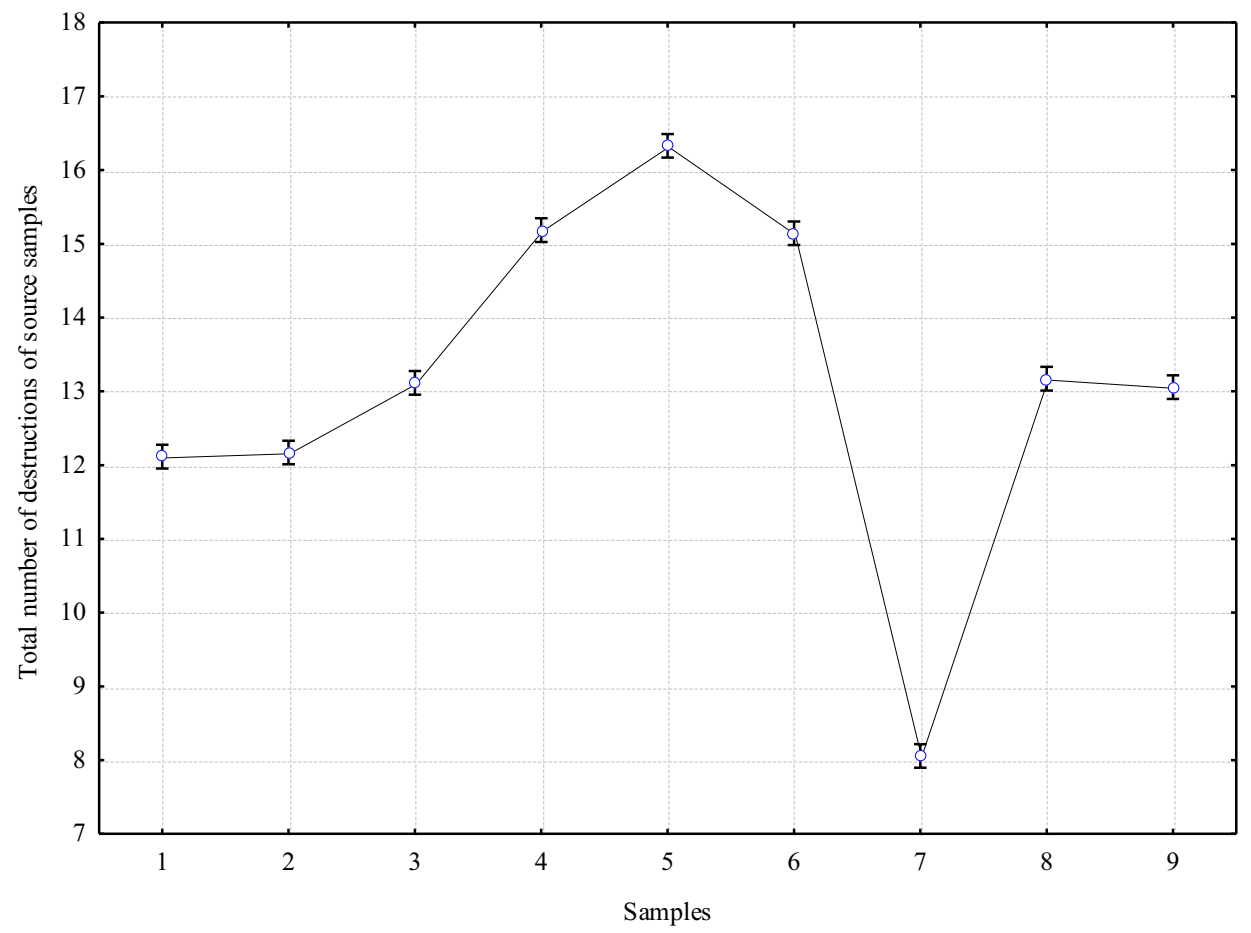

Fig. 1. ANOVA of total numbers of destructions "N". Source samples of fabrics. Vertical bars denote confidence intervals for means.

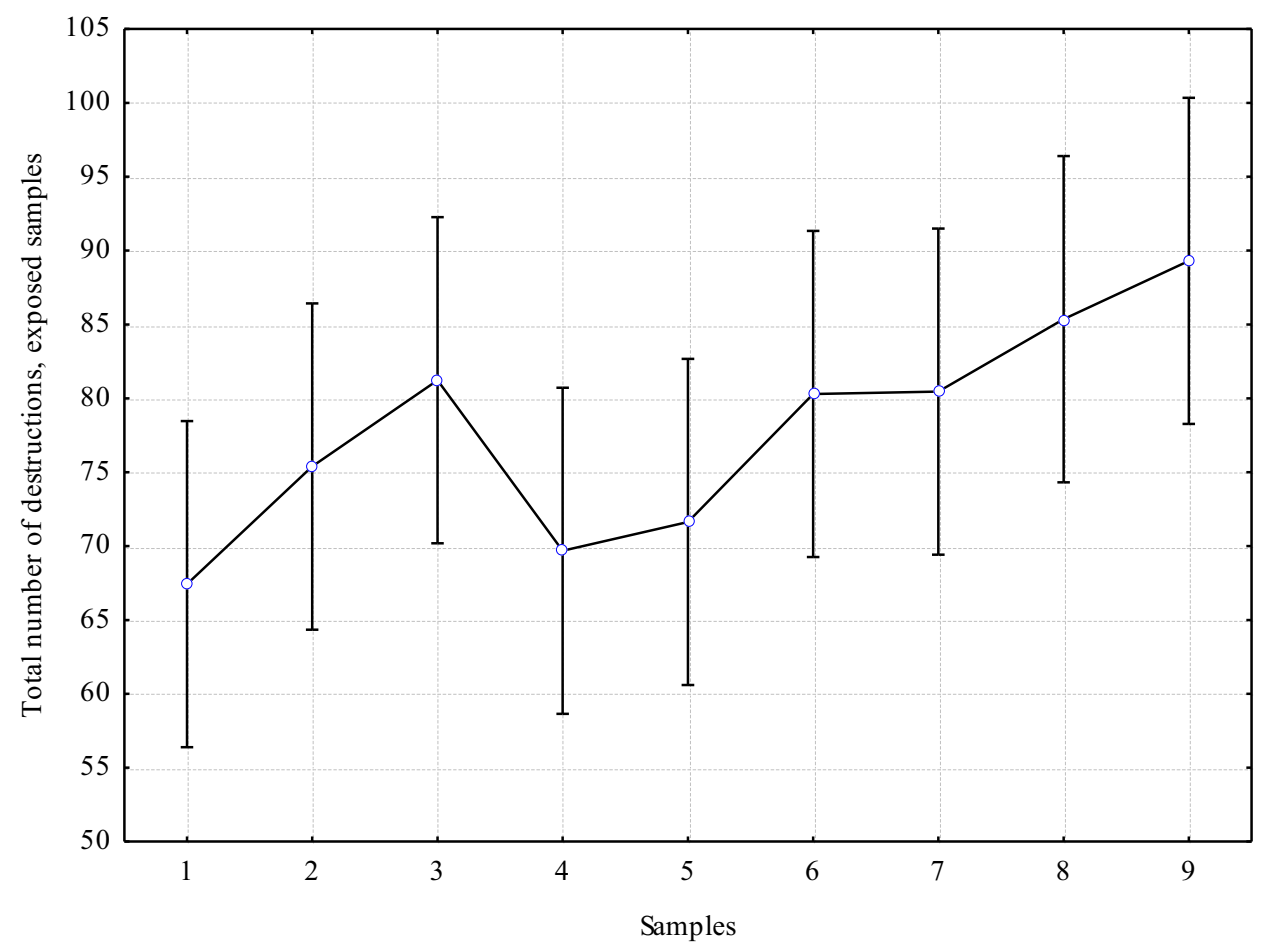

Fig. 2. ANOVA of total numbers of destructions "N". Exposed samples of fabrics. Vertical bars denote confidence intervals for means. 


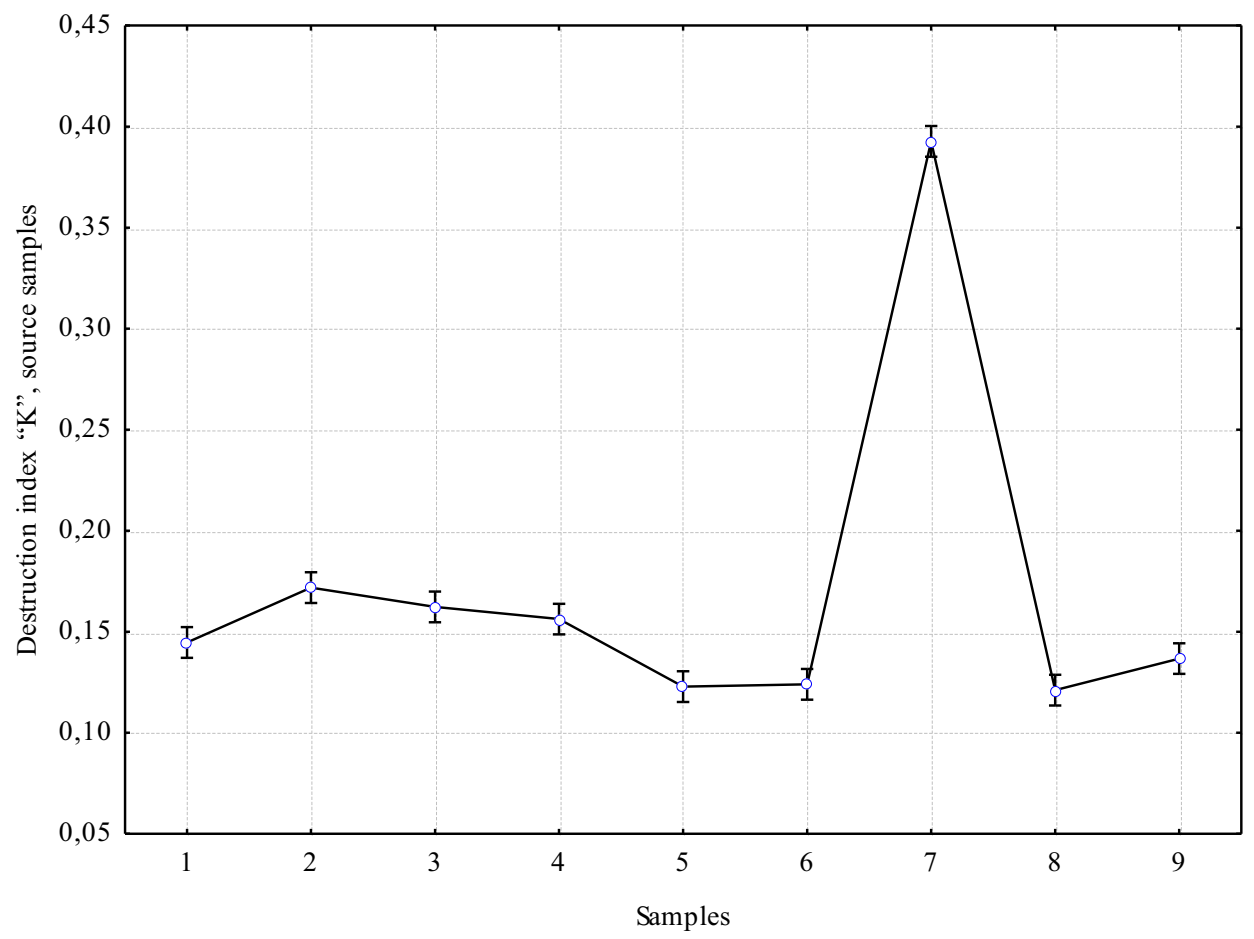

Fig. 3. ANOVA of total numbers of destruction index "K". Source samples of fabrics. Vertical bars denote confidence intervals for means.

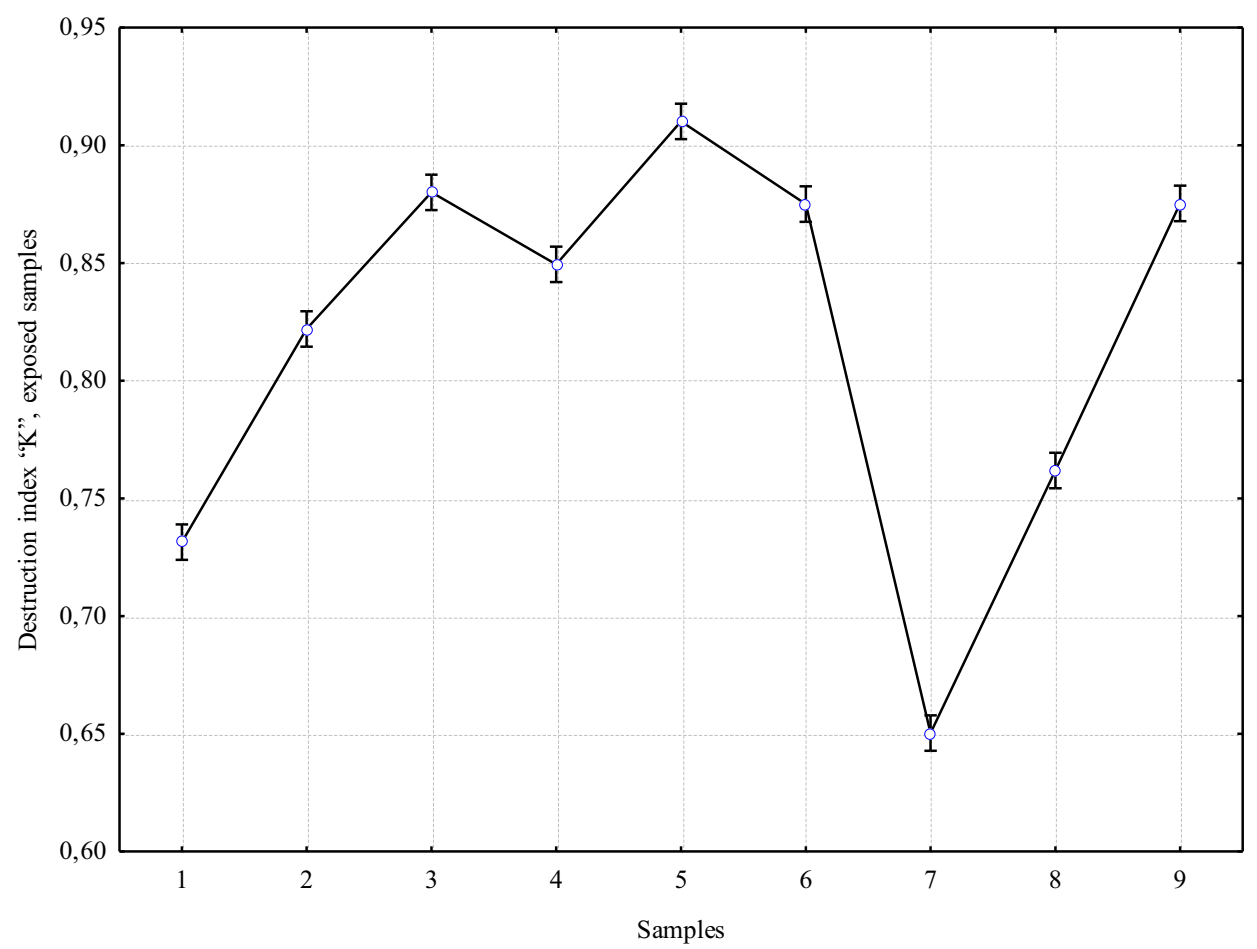

Fig. 4. ANOVA of total numbers of destruction index "K". Exposed samples of fabrics (8 month of exposure). Vertical bars denote confidence intervals for means. 


\section{Conclusion}

The data obtained based on the evaluation of the biostability of fabrics made from various textile fibers showed that the usage of natural silk, hemp and polyester as well able to supply to textile fibers resistance to biodegradation by spontaneous microflora from the surfaced air. According to our data, fabric samples containing hemp had zones of absence from microflora growth on fibers inside the tissues. Silk fibers also had zones free from microflora. It indicated the inhibition of the development of fiber destructors. At the same time, cotton fibers were actively colonized by microflora, which destroyed them.

This paper publication was partially supported by the Ministry of Education and Science of the Russian Federation within the program to improve the competitiveness of Peter the Great St. Petersburg Polytechnic University (SPbPU) among the world's leading research and education centers in the 2016-2021. The presented research performed within the framework of the State Assignment No 0662-2019-0001 (oil and fibre crop: evaluation and enlarge of genotypic variability), AAA-A19119013090159-5 commissioned to VIR.

\section{References}

1. K. Illarionova, S. Grigoryev, E3S Web of Conferences 164, 06015 (2020)

2. R.L Górny, A. Ławniczek-Wałczyk, A. Stobnicka, M. Gołofit-Szymczak, M. Cyprowski, Med. Pracy. 66, 4, 511-523 (2015)

3. B.B. Jarvis, J.D. Miller, App. Microb. and Biotech. 66, 4, 367-372 (2005)

4. M. Gołofit-Szymczak, R.L. Górny, Indoor Air. 28, 6, 792-805 (2018)

5. J. Gościcki, L. Włodarczyk, G. Bielichowska, Med. pracy 31, 2, 91-97 (1980)

6. M.D Lougheed, J.O. Roos, W.R. Waddell, P.W. Munt, Chest 108, 5, 1196-1200 (1995)

7. K. Illarionova, S. Grigoryev, I. Asfondiarova, IOP Conf. Series: Mater. Sc. and Eng. 012110 (2019)

8. N.S.Dymnikova, E.V. Erohina, A.P. Moryganov, S.V.Grigorev, O.Y. Kuznetsov, Inorganic Mater.: Appl. Res. 11, 2, 385-393 (2020)

9. O. Kotomenkova, A. Vinogradova, 16, 4,1742-1751 (2018)

10. O. Kotomenkova, A. Vinogradova, IOP Conf. Series: Mater. Sci. and Eng., 940, 1, 012080 (2020) 